\title{
Activation of complement by renal tissues from patients with IgA nephropathy
}

\author{
Y TOMINO, M ENDOH, Y NOMOTO, AND H SAKAI \\ From the Department of Internal Medicine, School of Medicine, Tokai University, \\ Isehara City, Kanagawa-ken, 259-11, Japan
}

SUMMARY In a study of complement activation by renal tissues, renal biopsy specimens were obtained from patients with IgA nephropathy and other glomerular diseases. These specimens were incubated with freshly frozen guinea-pig serum, and the activation of guinea-pig complement systems was evaluated by immunofluorescent staining with FITC-conjugated anti-guinea-pig complement antisera. It was shown that the alternative pathway of the complement was activated in situ in renal tissues from patients with IgA nephropathy. It is suggested that analysis of in situ activation of complement in such patients is useful for elucidating the mechanism of complement activation in various glomerular diseases.

IgA nephropathy is characterised by mesangial deposition of IgA with less intense deposition of IgG, IgM, and $\mathrm{C} 3$ in patients without evidence of systemic diseases. ${ }^{12}$ Although the pathogenesis of IgA nephropathy is still obscure, the complement system activated in IgA nephropathy is mainly via the alternative pathway. ${ }^{3} 4$

The aim of the present study was to demonstrate the fixation of guinea-pig complement by glomerular deposits of immunoglobulins in renal biopsy specimens from patients with IgA nephropathy and other types of primary glomerulonephritis. The results of this study indicated the in situ activation of alternative pathways of complement in renal biopsy specimens from such patients.

\section{Material and methods}

Renal biopsy specimens were obtained from 15 patients with IgA nephropathy. Routine microscopic, immunofluorescent, and electron microscopic analyses were performed for the diagnosis of IgA nephropathy. Patients whose biopsy specimens stained predominantly for IgA in mesangial areas were included in this study after exclusion of patients with systemic lupus erythematosus, anaphylactoid purpura, or other systemic diseases. The histopathological changes in our studies were classified as IgA nephropathy 'minimal' (grade I), 'slight' (grade II), 'moderate' (grade III), and 'advanced' (grade IV)

Accepted for publication 11 June 1980 stages. Thirteen patients with other types of chronic glomerulonephritis were also examined. Among these were four patients with chronic proliferative glomerulonephritis, three patients with membranoproliferative glomerulonephritis, four patients with membranous nephropathy, and two patients with minimal change.

Renal biopsy specimens were embedded and rapidly frozen in acetone dry ice, sectioned to 2 to $3 \mu$ with a rotary microtome in a cryostat at about $-25^{\circ} \mathrm{C}$, and air-dried. Immediately before staining, sections were washed three times in phosphate buffered isotonic saline (PBS, pH 7.2) for 15 minutes. Fluorescein-labelled antisera to anti human IgG, IgM, IgA, IgE (heavy chain specific), $\mathrm{Clq}, \mathrm{C} 4$, and $\mathrm{C} 3$ were obtained from Behringwerke AG (MarburgLahn, West Germany) ( $\mathbf{F} / \mathbf{P}$ molar ratios ranged from 1.8 to $2 \cdot 9$ ). Fluorescein-labelled antisera to anti human C5 was obtained from the Medical and Biological Laboratories (Tokyo, Japan) (F/P molar ratio 1.9). Fluorescein-labelled antisera to anti human properdin were obtained from the Kent Laboratories (Redmond, USA) (F/P molar ratio 3.5). Indirect immunofluorescent studies were performed using rabbit antisera to human $\mathrm{C} 3$ activator (C3A) and C9 obtained from Behringwerke AG. FITC-labelled goat anti rabbit Ig sera were obtained from Behringwerke AG (F/P molar ratio 4.0). Specificities of these antisera were determined by immunodiffusion and immunoelectrophoresis. These antisera were absorbed three times with mouse liver acetone powder. Dilution of antisera was 1:10 in 
PBS. Cryostat sections of the renal biopsy specimens were stained with these fluorescein-labelled antisera in a moist chamber at $4^{\circ} \mathrm{C}$ overnight. The sections were incubated with antisera to human $\mathrm{C} 3 \mathrm{~A}$ and $\mathrm{C} 9$ in a moist chamber at $4^{\circ} \mathrm{C}$ overnight. The sections were washed with PBS and then stained with the FITC-labelled goat anti rabbit Ig sera at room temperature for 2 hours.

Serum samples from guinea-pigs (GP) were separated from blood clotted at room temperature for 90 to 120 minutes and then stored at $-70^{\circ} \mathrm{C}$. Fluorescein-labelled antisera to anti GP C4 (FITCGP C4) were obtained from Medical and Biological Laboratories (F/P molar ratio 1.5). Fluoresceinlabelled antisera to anti GP C3 (FITC-GP C3) were obtained from the Cappel Laboratories (Cochranville, $\mathrm{Pa}$, USA) (F/P molar ratio 3.6$)$ and from Medical and Biological Laboratories (F/P molar ratio 1-2). Rabbit anti GP Clq was obtained from Medical and Biological Laboratories and conjugated with FITC (FITC-GP C1q) using the method of Kawamura. ${ }^{5}$ These sera were then absorbed with normal human serum (blood type $\mathrm{AB}$ ) at $4^{\circ} \mathrm{C}$ overnight. Specificities of these antisera were determined by immunodiffusion and immunoelectrophoresis. Specificity and cross-reactivity of FITClabelled anti GP complement and human sera were not observed by these immunochemical techniques. However, immunopathological staining of kidney specimens by these FITC-labelled antisera showed that certain of these antisera had some crossreactivity with human serum proteins. Such antisera were excluded before this study. Dilution of these antisera was 1:10 in PBS. Cryostat sections were initially incubated with GP serum, which was diluted 1:10 with veronal buffer containing calcium and magnesium in a moist chamber at $37^{\circ} \mathrm{C}$ for 1 hour. The sections were washed with PBS and then stained with FITC-labelled anti-GP C1q, C4, and C3 in a moist chamber at $4^{\circ} \mathrm{C}$ overnight. ${ }^{6}$ Other sections were stained with FITC-labelled anti GP C1q, C4, and $\mathrm{C} 3$ alone to determine whether there was nonspecific fluorescence or cross-reactions between anti GP sera and human serum components. Other sections were also incubated with heat-inactivated GP serum and then stained with FITC-GP C1q, $\mathrm{C} 4$, and $\mathrm{C} 3$. Moreover, some sections were incubated with GP serum and then stained with FITC-GP $\mathrm{Clq}, \mathrm{C} 4$, and $\mathrm{C} 3$ which had been previously absorbed by fresh GP serum.

The sections were washed with PBS and then covered with buffered glycerol and a cover slip and examined with a Zeiss Orthoflux microscope (Model 9902; Carl Zeiss, Inc, New York, NY). The intensity of the fluorescence was graded as none $(-)$, trace $( \pm), 1(+), 2(+)$, and $3(+)$.

Quantitation of serum IgA was performed using Tri-Partigen ${ }^{\circledR}$ plates (Behring Diagnostics, Sommerville, New Jersey, USA) and that of C3, C4 was carried out using M-Partigen ${ }^{\circledR}$ plates (Behring Diagnostics).

Soluble immune complexes in sera were measured by a Clq-binding enzyme assay kit (Special Reference Laboratory, Tokyo, Japan). The normal value was less than $1.5 \mu \mathrm{g} / \mathrm{ml}$.

Chi square analysis was used in all statistical comparisons between individual study groups.

\section{Results}

The results of the immunofluorescent studies on patients with IgA nephropathy are summarised in Table 1. IgA was the prominent class of immunoglobulin noted in the glomeruli of all patients examined. Four types of $\operatorname{IgA}$ nephropathy were classified according to the classes of immuno-

Table 1 Immunofluorescent findings and histopathological changes in IgA nephropathy

\begin{tabular}{|c|c|c|c|c|c|c|c|c|c|c|c|c|c|c|c|c|}
\hline Case & Sex & $\begin{array}{l}\text { Age at } \\
\text { biopsy } \\
\text { (years) }\end{array}$ & $\begin{array}{l}\text { Histopathological } \\
\text { changes }\end{array}$ & $\operatorname{Ig} A$ & $I g G$ & $I g M$ & $C l q$ & $C 4$ & $C 3$ & $C 5$ & $C 9$ & $P$ & $C 3 A$ & $G P-C$ & $G P-C 4$ & $G P-C 3$ \\
\hline 1 & $\mathbf{M}$ & 23 & I & +++ & + & \pm & - & - & + & + & $+t$ & ND & + & - & - & + \\
\hline 2 & $\mathbf{M}$ & 38 & I & ++ & + & + & + & \pm & + & ND & ++ & \pm & \pm & - & - & ND \\
\hline 3 & $\mathbf{M}$ & 27 & II & $t+t$ & \pm & + & + & + & ++ & \pm & \pm & 土 & \pm & - & - & + \\
\hline 4 & $\mathbf{M}$ & 26 & II & $++t$ & + & \pm & \pm & \pm & ++ & + & $+t+$ & + & + & - & - & ++ \\
\hline 5 & $\mathbf{M}$ & 28 & II & $++t$ & - & - & - & - & ++ & ND & ND & - & + & - & - & + \\
\hline 6 & $\mathbf{M}$ & 35 & II & $+t+$ & - & - & - & - & ++ & ND & \pm & - & \pm & - & - & - \\
\hline 7 & $\mathbf{M}$ & 33 & II & $+t+$ & - & - & - & - & ++ & ND & + & \pm & \pm & - & - & - \\
\hline 8 & $\mathbf{M}$ & 23 & II & $++t$ & + & + & + & + & +++ & ND & ++ & \pm & + & - & - & + \\
\hline 9 & $\mathbf{M}$ & 17 & II & $+t+$ & + & + & \pm & \pm & +++ & ND & ++ & + & + & - & - & ++ \\
\hline 10 & $\mathbf{F}$ & 30 & II & $++t$ & \pm & + & \pm & + & ++ & ++ & ++ & + & \pm & - & \pm & + \\
\hline 11 & $\mathbf{F}$ & 38 & II & +++ & - & + & \pm & \pm & + & + & \pm & \pm & \pm & ND & ND & + \\
\hline 12 & F & 22 & II & ++ & - & - & - & - & + & \pm & \pm & \pm & - & - & \pm & \pm \\
\hline 13 & $\mathbf{M}$ & 25 & III & +++ & \pm & + & \pm & ND & $++t$ & ND & ND & \pm & ND & - & - & $+t$ \\
\hline 14 & $\mathbf{F}$ & 24 & III & +++ & + & + & + & - & ++ & ++ & + & \pm & - & + & - & + \\
\hline 15 & $\mathbf{F}$ & 29 & IV & $+t+$ & + & \pm & + & \pm & +++ & ND & $+t+$ & - & $-t$ & - & - & + \\
\hline
\end{tabular}

$P=$ properdin $;$ ND $=$ not done. 


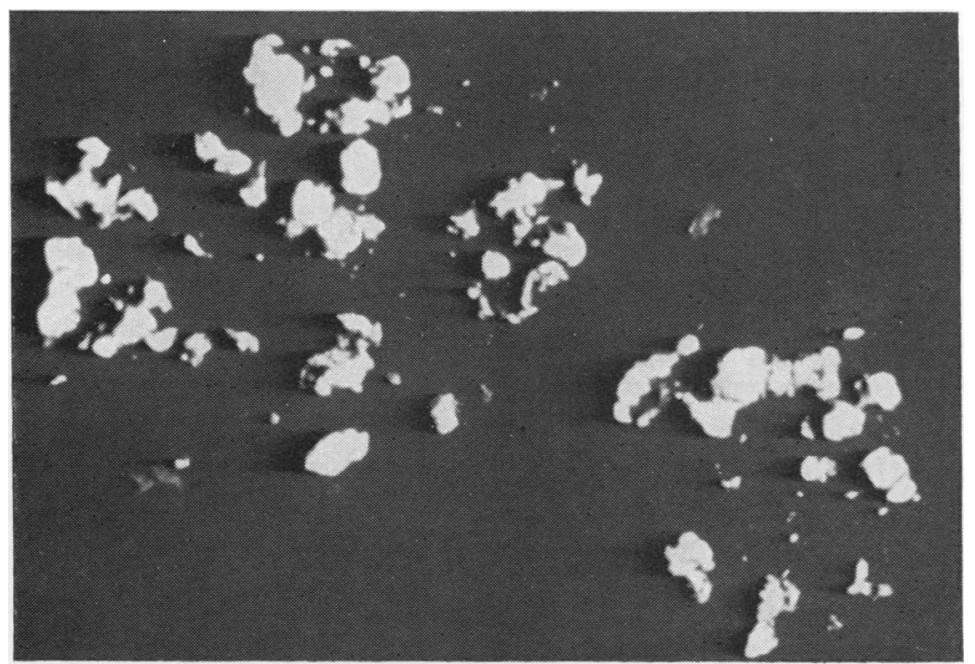

Fig. 1 Immunofluorescent localisation of IgA in glomeruli. Renal biopsy specimens stained with FITC-conjugated heavy chain specific anti human $\operatorname{IgA}$. See text for details of the staining procedure.

globulins deposited in the glomeruli, that is, deposits of $\operatorname{Ig} A$ alone, $\operatorname{IgA}$ and $\operatorname{IgG}, \operatorname{Ig} A$ and $\operatorname{IgM}$, and $\operatorname{IgA}$, IgG, and IgM. In four cases, $\operatorname{IgA}$ was the only immunoglobulin detected in the glomeruli. In three cases, IgA was detected in association with IgG. In four cases, $\operatorname{IgA}$ was detected with IgM, while in four cases, IgA was detected with IgG and IgM. The intensity of IgG and IgM deposition was always less than that of IgA deposition (Fig. 1).

Clq was observed in five out of 15 cases. C4 was observed in three out of 14 cases. Although $\mathrm{Clq}$ and $\mathrm{C} 4$ were not found in the cases with deposits of $\operatorname{IgA}$ only, these components were observed in the cases with combined deposits of immunoglobulins.

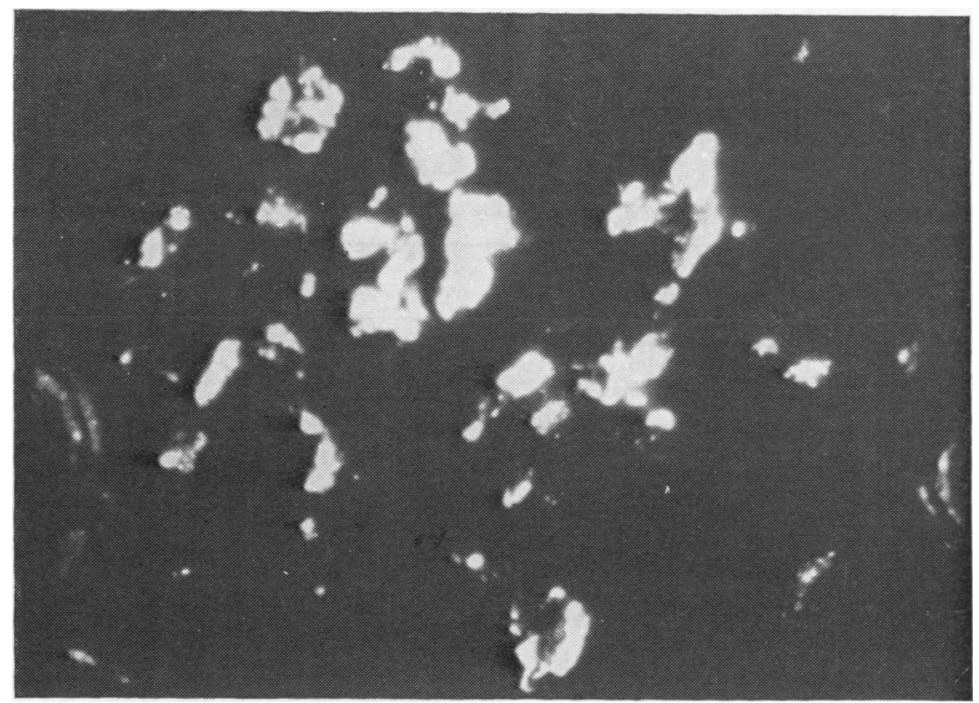

Fig. 2 Immunofluorescent localisation of C3 in glomeruli. Renal biopsy specimens stained with FITC-conjugated anti human C3. See text for details of the staining procedure. 


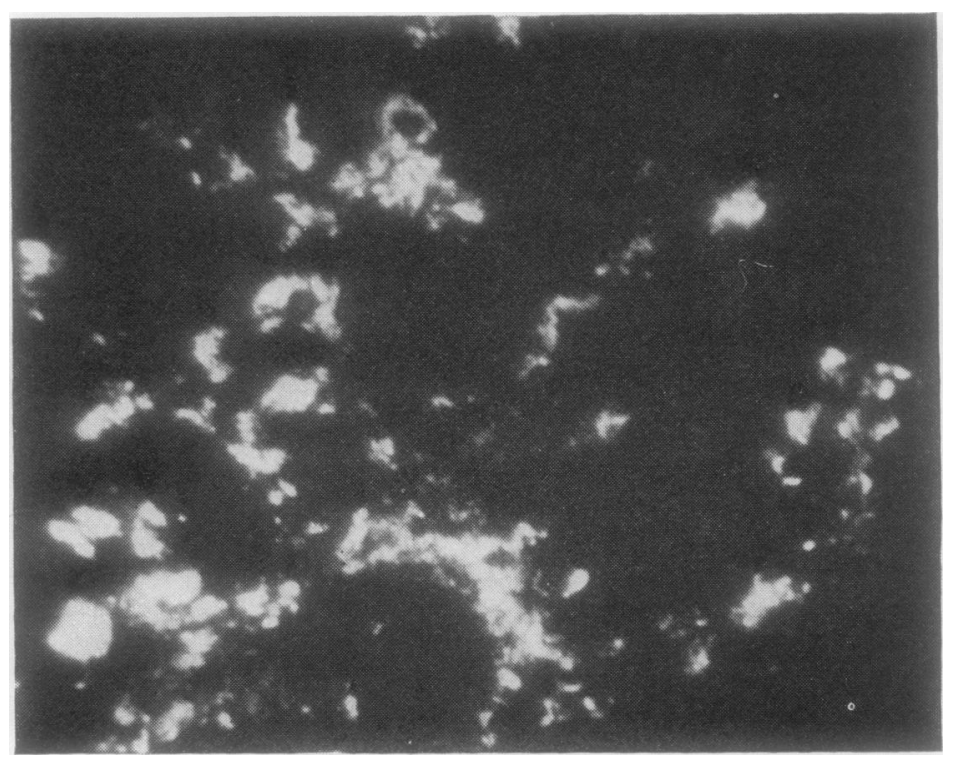

Fig. 3 Immunofluorescent localisation of guinea-pig C3 in glomeruli. Renal biopsy specimens stained with FITC-conjugated anti-guinea-pig C3. See text for details of the staining procedure.

Prominent deposition of $\mathrm{C} 3$ was observed in all cases tested. C3 was observed in all four cases in which IgA occurred as the sole immunoglobulin. In the cases with combined deposits of immunoglobulins, C3 was observed in all cases tested (Fig. 2). C5 was observed in five out of seven cases tested. C9 was observed in nine out of 13 cases tested. Properdin was observed in three out of 14 cases, although all of these cases were those with combined deposits of immunoglobulins. C3A was observed in six out of 14 cases, although five out of these six cases were those with combined deposits of immunoglobulins. The distribution pattern of properdin and C3A was almost identical with that of IgA and $\mathrm{C} 3$.

Deposition of FITC-GP Clq was observed in only one out of 14 cases, and that of FITC-GP C4 in none of the 14 cases. On the other hand, the deposition of FITC-GP C3 was observed in 11 out of 14 cases tested. The distribution pattern of FITC-GP C3 was almost identical with that of IgA and C3 (Fig. 3). Higher incidences of glomerular deposition of these complement components were observed in

Table 2 Serum concentrations of Ig A, C3, C4, and soluble immune complex in Ig A nephropathy

\begin{tabular}{|c|c|c|c|c|}
\hline Case & $\begin{array}{l}\text { Serum } \operatorname{Ig} A \\
(m g / d l)\end{array}$ & $\begin{array}{l}\text { Serum } C 3 \\
(m g / d l)\end{array}$ & $\begin{array}{l}\text { Serum } C 4 \\
(m g / d l)\end{array}$ & $\begin{array}{l}\text { Soluble immune complex } \\
(\mu \mathrm{g} / \mathrm{ml})\end{array}$ \\
\hline 1 & 193.0 & $73 \cdot 0$ & $30 \cdot 0$ & $30 \cdot 0$ \\
\hline 2 & $249 \cdot 0$ & ND & ND & $<1.5$ \\
\hline 3 & $547 \cdot 0$ & $72 \cdot 0$ & $31 \cdot 0$ & ND \\
\hline 4 & $258 \cdot 0$ & $67 \cdot 0$ & ND & $4 \cdot 5$ \\
\hline 5 & $301 \cdot 0$ & $73 \cdot 0$ & $40 \cdot 0$ & $3 \cdot 9$ \\
\hline 6 & $330 \cdot 0$ & $97 \cdot 0$ & $33 \cdot 0$ & $<1.5$ \\
\hline 7 & $410 \cdot 0$ & $62 \cdot 0$ & ND & ND \\
\hline 8 & $453 \cdot 0$ & $88 \cdot 0$ & $35 \cdot 0$ & $<1.5$ \\
\hline 9 & $334 \cdot 0$ & $68 \cdot 0$ & ND & $<1.5$ \\
\hline 10 & $292 \cdot 0$ & $65 \cdot 0$ & ND & $<1.5$ \\
\hline 11 & $375 \cdot 0$ & $76 \cdot 0$ & $35 \cdot 0$ & 1.9 \\
\hline 12 & $183 \cdot 0$ & $84 \cdot 0$ & ND & ND \\
\hline 13 & $342 \cdot 0$ & $70 \cdot 0$ & $64 \cdot 0$ & $<1.5$ \\
\hline 14 & $358 \cdot 0$ & $87 \cdot 0$ & $48 \cdot 0$ & ND \\
\hline 15 & $399 \cdot 0$ & $88 \cdot 0$ & $53 \cdot 0$ & ND \\
\hline Mean $\pm \mathrm{SD}$ & $334.9 \neq 96 \cdot 5^{*}$ & $76.4 \pm 10.5$ & $41 \cdot 1 \pm 11 \cdot 5$ & $\ldots$ \\
\hline
\end{tabular}

$\mathrm{ND}=$ not done $;{ }^{*} \mathrm{P}<0.001$. 
patients with grades II and III IgA nephropathy. The correlation between the histopathological changes and the intensity of $\operatorname{IgA}, \mathrm{C} 3$, and FITC-GP $\mathrm{C} 3$ deposition was significant $(\mathrm{P}<0.001)$. No significant relation was observed between the intensity of C3 deposition and that of FITC-GP C3 deposition. In addition, no significant relation was observed between the intensity of $\operatorname{IgA}$ deposition and that of FITC-GP C3 deposition. The deposition of FITC-GP $\mathrm{Clq}, \mathrm{C} 4$, and $\mathrm{C} 3$ was not observed using heatinactivated GP serum, FITC-GP Clq, C4, or C3 which were absorbed with fresh GP sera.

The levels of serum $\operatorname{IgA}$ in patients with $\operatorname{IgA}$ nephropathy were significantly higher than those in healthy controls $(P<0.001)$. The levels of serum C3 and $\mathrm{C} 4$ did not change in patients with IgA nephropathy. There were no significant correlations between the serum $\mathrm{C} 3$ level and the glomerular deposition of C3 or FITC-GP C3 (Table 2).

In three patients with membranoproliferative glomerulonephritis (MPGN), Clq, C4 and C3 were observed in all cases tested. Although FITC-GP Clq was not observed, FITC-GP C3 was observed in all patients with MPGN. FITC-GP C4 was observed in one out of three patients with MPGN. $\mathrm{Clq}, \mathrm{C4}$, and $\mathrm{C} 3$ were observed in three out of four patients with membranous nephropathy. Although FITC-GP Clq was observed in one out of four cases, FITC-GP C4 and C3 were observed in all patients with membranous nephropathy tested. FITC-GP $\mathrm{Clq}, \mathrm{C} 4$, and $\mathrm{C} 3$ were not observed in patients with chronic proliferative glomerulonephritis and minimal change.

Soluble immune complexes (IC) were detected in four out of 10 patients with $\operatorname{IgA}$ nephropathy (Table 2). IC was detected in three out of six patients with MPGN, in one out of four patients with membranous nephropathy, and in three out of four patients with chronic proliferative glomerulonephritis. IC was not detected in cases of minimal change.

\section{Discussion}

IgA nephropathy is characterised by mesangial deposition of IgA in renal biopsy specimens with immunofluorescent staining. ${ }^{1}$ Although IgA nephropathy is usually presumed to be a type of immune complex-mediated glomerulonephritis, the pathogenesis of this disorder is still obscure. IgA has been shown to fix complement mainly through the alternative pathway ${ }^{7}$ and, to some extent, by the classical pathway. It has been reported that the complement system of $\operatorname{IgA}$ nephropathy was activated mainly at $\mathrm{C} 3$ via the alternative pathway by IgA. ${ }^{34}$ The results obtained in this study showed that glomerular deposition of early complement components $(\mathrm{Clq}$ and $\mathrm{C} 4)$ was completely absent in cases with glomerular deposition of $\operatorname{IgA}$ only although late complement components (C3, C5, and C9) were present in a pattern similar to that of $\operatorname{IgA}$ deposition. It is assumed that these late components were activated via the alternative pathway. This assumption was supported by the fact that glomerular deposition of properdin and $\mathrm{C} 3 \mathrm{~A}$ was demonstrated in most cases; this finding was consistent with those of Evans et al. ${ }^{8}$ and McCoy et al. ${ }^{3}$

Although fixation of FITC-GP Clq and $\mathrm{C} 4$ was not detected in the glomeruli, that of FITC-GP C3 was observed in most cases with IgA nephropathy. Distribution of FITC-GP C3 deposition was similar to that of $\mathrm{C} 3$ and IgA. These observations also supported the concept that the complement system of IgA nephropathy is activated via the alternative pathway. There were significant correlations between the histopathological changes and the intensity of IgA, C3, or FITC-GP C3 deposition in IgA nephropathy.

A low incidence of circulating immune complexes was observed in IgA nephropathy. Circulating immune complexes in patients with IgA nephropathy were detected in the cases with polyclonal deposition of immunoglobulins in IgA nephropathy, indicating that the classes of immunoglobulins in these C1qbinding immune complexes were IgG and/or IgM.

It is concluded that the results from the present study indicated the in situ activation of the alternative pathway of the complement in mesangial areas of renal biopsy specimens from patients with $\operatorname{IgA}$ nephropathy. Further evaluation of the correlation between the degree of complement activation by renal tissues and the severity of the prognosis in these patients is warranted.

We are grateful to Professor Shigeru Arimori for his helpful support.

\section{References}

${ }^{1}$ Berger J. IgA glomerular deposits in renal disease. Transplant Proc 1969;1:939-44.

${ }^{2}$ Zimmerman SW, Burkholder PM. Immunoglobulin A nephropathy. Arch Intern Med 1975;135:1217-23.

${ }^{3}$ McCoy RC, Abramowsky CR, Tisher CC. IgA nephropathy. Am J Pathol 1974;76:123-40.

- Tomino Y. Complement system in IgA nephropathy. Tokai J Exp Clin Med 1980;5:15-22.

${ }^{5}$ Kawamura A. Staining methods. In: Fluorescent Antibody Techniques and their Applications. 2nd ed. Tokyo: University of Tokyo Press, 1977.

${ }^{6}$ Burkholder PM. Complement fixation in diseased tissues: I. Fixation of guinea pig complement in sections of kidney from humans with membranous glomerulonephritis and rats injected with anti-rat kidney serum. J Exp Med 1961;114:605-16. 
7 Götze O, Müller-Eberhard HJ. The C3-activator system: An alternate pathway of complement activation. $J$ Exp Med $1971 ; 134$ (Suppl.) :90S.

${ }^{8}$ Evans DJ, Williams DG, Peters DK, et al. Glomerular deposition of properdin in Henoch-Schönlein syndrome and idiopathic focal nephritis. Br Med J 1973;3:326-8.
Requests for reprints to: Dr Yasuhiko Tomino, Department of Internal Medicine, School of Medicine, Tokai University, Isehara City, Kanagawa-ken, 259-11, Japan.

\section{The December 1980 Issue}

\section{THE DECEMBER 1980 ISSUE CONTAINS THE FOLLOWING PAPERS}

Histological evidence of initiating factors in acute necrotising pancreatitis in man AK FOULIS

Brain damage in fatal non-missile head injury J HUME ADAMS, DI GRAHAM, GRACE SCOTT, LILIAN S PARKER, AND D DOYLE

Senile amyloidosis: a protean manifestation of the aging process GG CORNWELL III AND P WESTERMARK

Megakaryocytes in pleural and peritoneal fluids: prevalence, significance, morphology, and cytohistological correlation NB KUMAR AND B NAYLOR

Primary clear cell carcinoma of the larynx $\mathrm{G}$ PESAVENTO, A FERLITO, AND G RECHER

Identification of group B streptococci in tissue sections using the peroxidase-antiperoxidase method: a retrospective necropsy study $T$ ANDRES AND B MACPHERSON

Role of coagulase-negative staphylococci and micrococci in ocular disease VM MAHAJAN, TA ALEXANDER, RK JAIN, AND LP AGARWAL

The diagnosis of Legionnaires' disease by counterimmunoelectrophoresis MG HOLLIDAY

Preliminary report on the pathogenicity of Legionella pneumophila for freshwater and soil amoebae TJ ROWBOTHAM

Electron microscopic evidence of flagella and pili on Legionella pneumophila FG RODGERS, PW GREAVES, AD MACRAE, AND MJ LEWIS
Detection of Bacteroides fragilis and Bacteroides melaninogenicus by direct immunofluorescence $M$ LABBÉ, N DELAMARE, F PEPERSACK, F CROKAERT, AND E YOURASSOWSKY

Cytoplasmic vacuolation of peripheral blood cells in acute alcoholism RJ DAVIDSON AND JL MCPHIE

Congenital dyserythropoietic anaemia type II (HEMPAS): a family study SHAUN R MCCANN, R FIRTH, NUALA MURRAY, AND IJ TEMPERLEY

Antithrombin III in patients on long-term oral anticoagulants H BULL, I MACKIE, M BROZOVIĆ, AND D WOODINGS

Heparin stability: effects of diluent, heparin activity, container, and pH KT GOODALL, CHEE-CHOONG CHOOI AND AS GALLUS

Ribonuclease as a tumour marker for pancreatic carcinoma G DORAN, TG ALLEN-MERSH, AND KW REYNOLDS

\section{Technical methods}

A simple method for processing fine-needle aspiration biopsy specimens for electron microscopy M AKHTAR, M ASHRAF ALI, E OWEN, AND M BAKRY

An economical, simplified haemagglutination test for mass syphilis screening JAJ BARBARA, R SALKER, FATIMA LALII, TD DAVIES, AND JB HARRIS

\section{Letters to the Editors}

\section{Book reviews}

Index to volume 33

Copies are still available and may be obtained from the PUBLISHING MANAGER, BRITISH MEDICAL ASSOCIATION, TAVISTOCK SQUARE, LONDON WC1H 9JR, price $£ 3.00$, including postage 